\title{
Adaptive Fuzzy Controller Design for Simulated Moving Bed System
}

\author{
Chao-Fan Xie, ${ }^{1,2}$ Huang-Chu Huang, ${ }^{3}$ Lin Xu, ${ }^{2}$ Yu-Ju Chen, ${ }^{4}$ and Rey-Chue Hwang ${ }^{1 *}$ \\ ${ }^{1}$ Department of Electrical Engineering, I-Shou University, \\ No. 1, Sec. 1, Syuecheng Rd., Dashu District, Kaohsiung City 84001, Taiwan \\ ${ }^{2}$ Electronic Information and Engineering Institute, Fujian Polytechnic Normal University, \\ No. 1, Long Jiang Street, Fuqing City 350300, Fuzhou City, Fujian Province, China \\ ${ }^{3}$ Department of Telecommunication Engineering, National Kaohsiung University of Science and Technology, \\ No. 142, Haijhuan Rd., Nanzih District, Kaohsiung City 81157, Taiwan \\ ${ }^{4}$ Department of Information Management, Cheng-Shiu University, \\ No. 840, Chengcing Rd., Niaosong District, Kaohsiung City 83347, Taiwan
}

(Received December 13, 2019; accepted August 25, 2020)

Keywords: simulated moving bed, chromatographic separation, adaptive fuzzy controller

The simulated moving bed process (SMB), recognized as one of the cleanest options for chromatographic separation, has been widely used in the biopharmaceutical and chemical industries. However, the complex and nonlinear behavior of SMB still poses concerns and challenges in current developments of its precision control. In this study, an adaptive fuzzy controller is designed and presented. Unlike the traditional fuzzy controller, three error terms, the purity error $(e)$, error change $(\Delta e)$, and the sum of errors $(\Sigma e)$, are used as the influencing parameters of the developed controller. The experimental results demonstrate the potential of adaptive fuzzy controllers in improving system robustness and implementing precision control in SMB.

\section{Introduction}

Chromatography is a technique used for the separation of a mixture. The simulated moving bed process (SMB) has had increasing application in large-quantity supercritical fluid extraction owing to its advantages such as a low production cost, a low solvent consumption, and its ability to carry out a clean, continuous operation. ${ }^{(1,2)}$ The basic principle of SMB is to use multiple columns containing the solid adsorbent and move these columns in the opposite direction to the fluid to achieve a countercurrent flow, hence the term "moving bed".

Among the chromatographic separation technologies, SMB has been recognized as a highly practical and excellent technique that requires little solvent or water while providing a high separation efficiency. ${ }^{(3,4)}$ SMB is a continuous operation technique that utilizes the adsorption principle to carry out the separation. The material inlet and outlet positions of the fixed bed can be changed at a fixed switching time. Compared with other fixed adsorption systems, SMB exhibits higher production capacity and separation efficiency. An example of the separation process of SMB is shown in Fig. 1.

*Corresponding author: e-mail: rchwang@isu.edu.tw https://doi.org/10.18494/SAM.2020.2735 


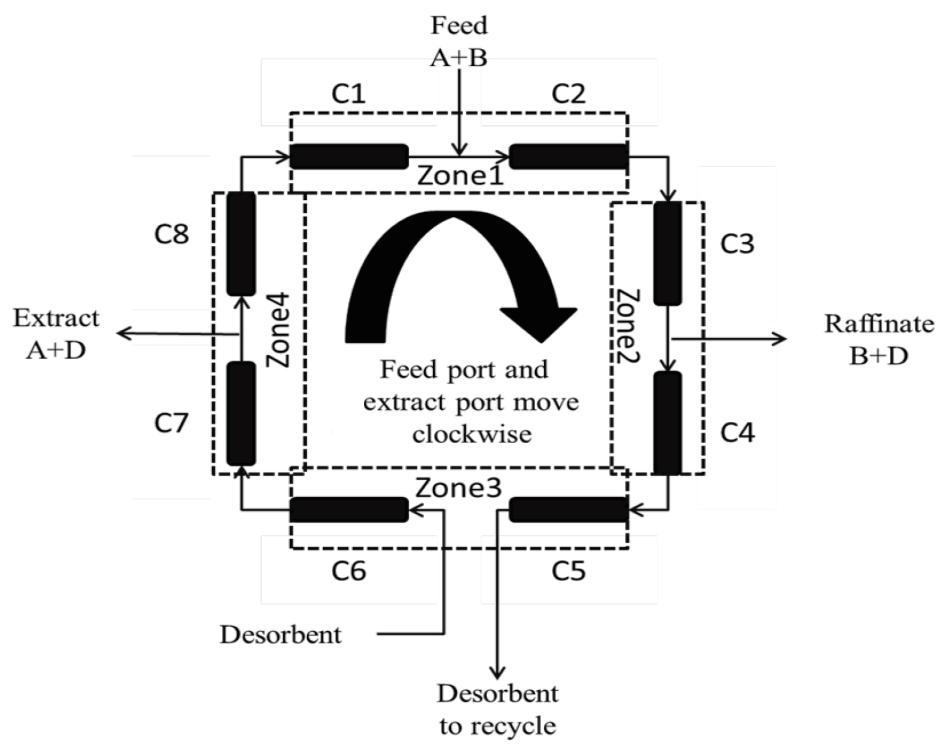

Fig. 1. Separation process of SMB.

However, the complex and nonlinear nature of SMB still poses a challenge in precision control for researchers and developers. An adaptive nonlinear model predictive control method was proposed by Andrade Neto et al. ${ }^{(5)}$ for the separation of enantiomers of praziquantel in a simulated moving bed. The primary focus of this model is to solve the problems of control speed and efficiency in the control framework.

In the classical linear model predictive controller (MPC), an improved prediction mechanism based on the strategy of switching the system was proposed by Nogueira et al. ${ }^{(6)}$ The results showed that this method can control the process in both servo and regulator cases. A method of optimizing separation control to improve the product purity and economic benefit was presented in Ref. 7. Lee and Seidel-Morgenstern proposed a method based on the results of a simulation study, in which the controller can estimate the current process state and find the best operation conditions under the competitive Langmuir isotherm. ${ }^{(8)}$ Yang et al. proposed an optimization strategy based on the improved moving asymptote algorithm, demonstrating that a controller based on the improved moving asymptote method can dynamically control SMB. ${ }^{(9)}$ A model predictive control method applied to SMB that is based on the established state-space model was presented by Martins et al. ${ }^{(10)}$

\section{Mathematical Model of SMB}

The mathematical model of SMB can be deduced from the true moving bed (TMB) model, which is described as follows. ${ }^{(11,12)}$ Table 1 gives the meanings of the SMB system's variables in the above equations. In the TMB model, the mass balance of the bulk phase is given by

$$
\frac{\partial C_{i, j}}{\partial t}=D_{i} \frac{\partial^{2} C_{i, j}}{\partial x^{2}}-v_{j}^{*} \frac{\partial C_{i, j}}{\partial x}-\frac{1-\varepsilon}{\varepsilon} k_{i}\left(q_{i j}^{*}-q_{i j}\right),
$$




$$
\frac{\partial q_{i, j}}{\partial t}=\frac{\partial}{\partial x} u_{s} q_{i j}+k_{i}\left(q_{i j}^{*}-q_{i j}\right) .
$$

For SMB, the mass balance of the bulk phase is given by

$$
\begin{gathered}
\frac{\partial C_{i, j}}{\partial t}=D_{i} \frac{\partial^{2} C_{i, j}}{\partial x^{2}}-v_{j}^{*} \frac{\partial C_{i, j}}{\partial x}-\frac{1-\varepsilon}{\varepsilon} k_{i}\left(q_{i j}^{*}-q_{i j}\right), \\
\frac{\partial q_{i, j}}{\partial t}=\frac{\partial}{\partial x} u_{s} q_{i j}+k_{i}\left(q_{i j}^{*}-q_{i j}\right) .
\end{gathered}
$$

The model can be converted as

$$
\begin{gathered}
\frac{\partial C_{i, j}}{\partial t}=D_{i} \frac{\partial^{2} C_{i, j}}{\partial x^{2}}-v_{j}^{*} \frac{\partial C_{i, j}}{\partial x}-\frac{1-\varepsilon}{\varepsilon} k_{i}\left(q_{i j}^{*}-q_{i j}\right), \\
\frac{\partial q_{i, j}}{\partial t}=k_{i}\left(q_{i j}^{*}-q_{i j}\right) .
\end{gathered}
$$

From Eqs. (5) and (6), we obtain

$$
\frac{\partial C_{i, j}}{\partial t}=D_{i} \frac{\partial^{2} C_{i, j}}{\partial x^{2}}-v_{j}^{*} \frac{\partial C_{i, j}}{\partial x}-\frac{1-\varepsilon}{\varepsilon} \frac{\partial q_{i, j}}{\partial t} .
$$

The adsorption equilibrium of two materials can be expressed by a linear isotherm,

$$
q_{i, j}=H_{i} C_{i, j},
$$

Table 1

Meanings of SMB system's variables.

\begin{tabular}{lc}
\hline Parameter & Meaning \\
\hline$x(\mathrm{~cm})$ & Axial distance \\
$k^{*}\left(\mathrm{gL}^{-1}\right)$ & Comprehensive mass transfer constant \\
$\left.v^{*}(\mathrm{~cm} \mathrm{~min})^{-1}\right)$ & Effective velocity of body \\
$u_{s}\left(\mathrm{~cm} \mathrm{~min}^{-1}\right)$ & Solid flow rate \\
$C\left(\mathrm{gL}^{-1}\right)$ & Mobile phase concentration \\
$q\left(\mathrm{gL}^{-1}\right)$ & Solid phase concentration \\
$q^{*}\left(\mathrm{gL}^{-1}\right)$ & Volume flow rate \\
$Q\left(\mathrm{~cm}^{3} \mathrm{~min}^{-1}\right)$ & Time \\
$t(\mathrm{~s})$ & Effective dispersion coefficient \\
$D\left(\mathrm{~cm}^{2} \min ^{-1}\right)$ & Bulk void fraction \\
$\varepsilon$ & Material index: $A$ or $B$ \\
$i$ & Column number: $1,2,3,4,5,6,7,8$ \\
$j$ & \\
\hline
\end{tabular}


where $H_{i}$ is the Henry coefficient, $i=A, B$, and $j=1, \ldots, 8$.

The purity formula can be calculated by

$$
\begin{gathered}
c_{E, B}=\frac{C_{E, B}}{C_{E, A}+C_{E, B}}, \\
c_{R, A}=\frac{C_{R, A}}{C_{R, A}+C_{R, B}},
\end{gathered}
$$

where $C_{E, B}$ represents the purity of $B$ from the extract outlet and $C_{R, A}$ represents the purity of $A$ from the raffinate outlet. The relationship between the effective velocity of the body $\left(v_{j}^{*}\right)$ and the volume flow rate $Q_{j}$ is described by

$$
v_{j}^{*}=\frac{Q_{j}}{\varepsilon \pi d^{2}},
$$

where $d$ is the radius of the column and $\varepsilon$ is the bulk void fraction.

\section{SMB Simulation}

To observe the system's behavior, a simulation of SMB is performed. The initial values of all the SMB's parameters are shown in Table 2. In this simulation, a 4-area with a 2-2-2-2 model is adopted.

Figures 2(a) and 2(b) display the variations in concentrations versus time. Figure 3 shows the concentration separation results of the two materials at the extract and raffinate outlets with different $H_{A}$ values.

From the results shown in Figs. 2 and 3, a high similarity can be observed between the simulation model and the real SMB system behavior. The agreement provides a promising condition for the controller we want to develop.

\begin{tabular}{|c|c|c|c|}
\hline Parameter & Value & Parameter & Value \\
\hline$L(\mathrm{~cm})$ & 29 & $\overline{C_{f, i}\left(\mathrm{gL}^{-1}\right)}$ & 6 \\
\hline$d(\mathrm{~cm})$ & 0.46 & $\theta(\min )$ & 3 \\
\hline$H_{A}$ & 0.01 & $Q_{I}\left(\mathrm{~cm}^{3} \min ^{-1}\right)$ & 7.1 \\
\hline$H_{B}$ & 0.45 & $Q_{I I}\left(\mathrm{~cm}^{3} \min ^{-1}\right)$ & 6.6 \\
\hline$D_{A}\left(\mathrm{~cm}^{2} \min ^{-1}\right)$ & 0.12 & $Q_{I I I}\left(\mathrm{~cm}^{3} \min ^{-1}\right)$ & 9.8 \\
\hline$D_{B}\left(\mathrm{~cm}^{2} \min ^{-1}\right)$ & 1.26 & $Q_{I V}\left(\mathrm{~cm}^{3} \mathrm{~min}^{-1}\right)$ & 4.5 \\
\hline time step $(\mathrm{s})$ & 0.1 & $\varepsilon$ & 0.8 \\
\hline space_step $(\mathrm{cm})$ & 0.1 & & \\
\hline
\end{tabular}

Table 2

Initial parameters for the separation. 


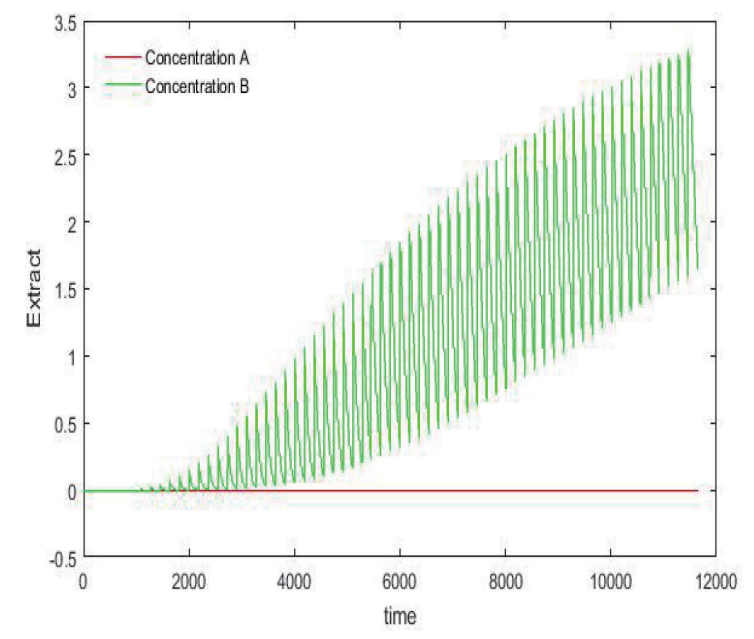

(a)

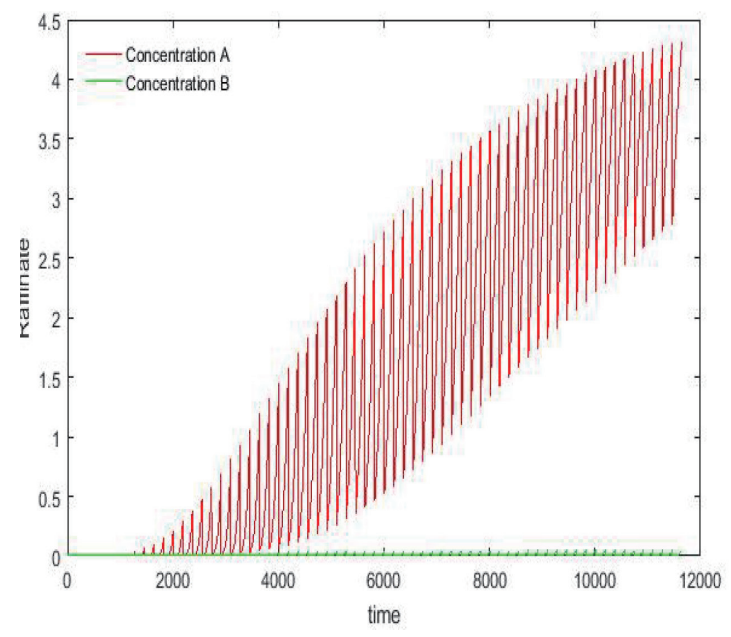

(b)

Fig. 2. (Color online) Concentration separation results of extract and raffinate outlets.

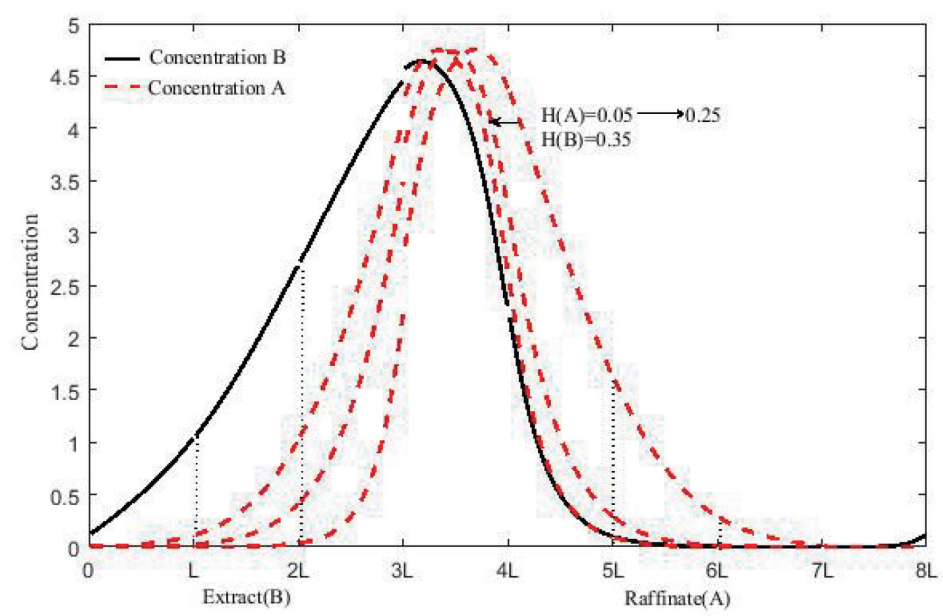

Fig. 3. (Color online) Variations in concentrations versus adsorption rate $\left(H_{A}\right)$.

\section{Adaptive Fuzzy Controller}

The fuzzy theory was first proposed by Professor Lotfi Zadeh in 1965. It is a knowledgebased or rule-based system containing many fuzzy IF-THEN rules. Usually, a complete fuzzy system is mainly composed of four parts, i.e., a fuzzifier, a fuzzy rule base, a fuzzy inference engine, and a defuzzifier. ${ }^{(13)}$ Fuzzy controllers have been widely employed in many linear and nonlinear control systems for their simplicity in design, especially for systems whose information is uncertain and unknown.

The control structure of the adaptive fuzzy control mechanism we developed is shown in Fig. 4. The controller is composed of two independent controllers: one is a traditional fuzzy controller and the other is a single-neuron controller. The neuron controller is used to compensate for the lack of precision control of the fuzzy controller. 


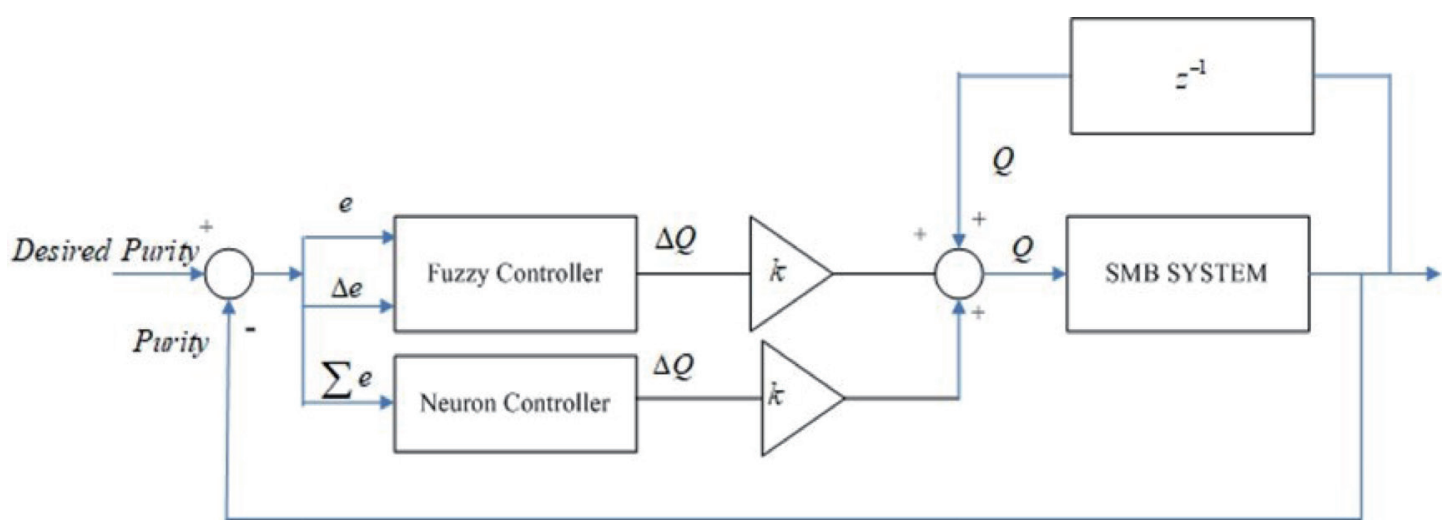

Fig. 4. (Color online) Structure of adaptive fuzzy controller.

In the whole SMB control process, the flow rates of Zones I $\left(Q_{1}\right)$, II $\left(Q_{2}\right)$, and III $\left(Q_{3}\right)$ are controlled by three individual adaptive fuzzy controllers. The variables of purity error $(e)$ and error change $(\Delta e)$ of materials $B$ and $A$ used as the fuzzy inputs are defined as follows, where $c_{E, B}$ and $c_{R, A}$ are the concentrations of $B$ and $A$ from the extract and raffinate outlets, respectively.

$$
\begin{gathered}
e_{1}=\text { desired } B-c_{E, B} \\
e_{2}=\text { desired } A-c_{R, A} \\
e_{3}=e_{1}+e_{2} \\
\Delta e_{1}=e_{1}(t)-e_{1}(t-1) \\
\Delta e_{2}=e_{2}(t)-e_{2}(t-1) \\
\Delta e_{3}=\Delta e_{1}+\Delta e_{2}
\end{gathered}
$$

Three controllers can generate the increment of their own flow rate $\left(\Delta Q_{i}, i=1,2,3\right)$. Figure 5 shows the membership functions of all error terms $\left(e_{i}\right.$ and $\left.\Delta e_{i}, i=1,2,3\right)$, and Fig. 6 presents the singleton membership function of the defuzzifier. Table 3 shows the fuzzy rule table used by the fuzzy controllers. The center values of $\left\{a_{1}, a_{2}, a_{3}, a_{4}, a_{5}\right\}$ for $\left(\Delta Q_{i}, i=1,2,3\right)$ are $\{0.15,0.1,0,-0.1,-0.15\},\{0.006,0.004,0,-0.004,-0.006\}$, and $\{0.08,0.05,0,-0.05,-0.08\}$, respectively.

The second controller is the single-neuron controller, which also generates the increment of the flow rate $\Delta Q$. As mentioned above, it is used to improve the drawback of the fuzzy controller to accomplish precision control. The model of the single-neuron controller is expressed as 


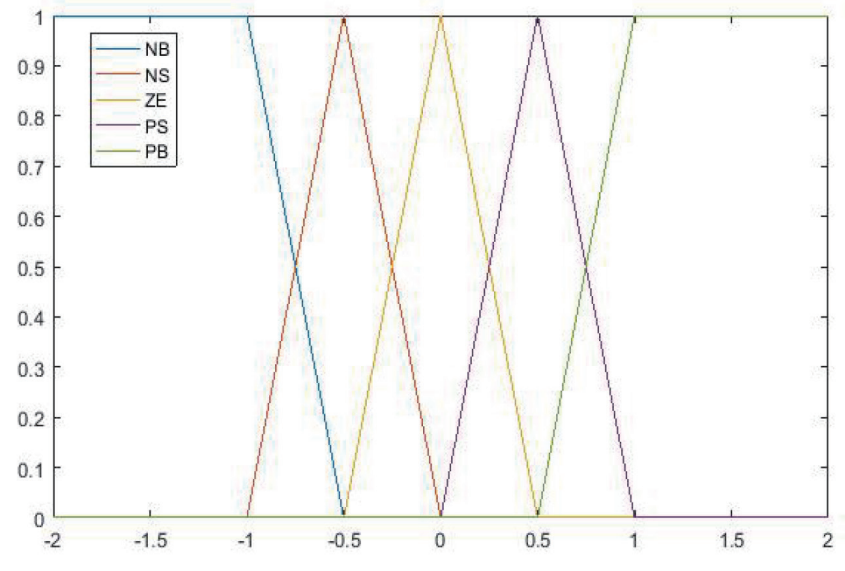

Fig. 5. (Color online) Membership functions of all error variables $\left(e_{i}\right.$ and $\left.\Delta e_{i}\right)$.

Table 3

Rule table of $\Delta Q_{i}, i=1,2,3$.

\begin{tabular}{|c|c|c|c|c|c|c|}
\hline & \multicolumn{5}{|c|}{$e$} \\
\hline & & $N B$ & $N S$ & $Z E$ & $P S$ & $P B$ \\
\hline \multirow{5}{*}{$\Delta e$} & $N B$ & $P 1$ & $P 1$ & $P 1$ & $P 2$ & $P 5$ \\
\hline & $N S$ & $P 1$ & $P 2$ & $P 2$ & $P 3$ & $P 5$ \\
\hline & $Z E$ & $P 1$ & $P 2$ & $P 3$ & $P 4$ & $P 5$ \\
\hline & $P S$ & $P 1$ & $P 3$ & $P 4$ & $P 4$ & $P 5$ \\
\hline & $P B$ & $P 1$ & $P 4$ & $P 5$ & $P 5$ & $P 5$ \\
\hline
\end{tabular}

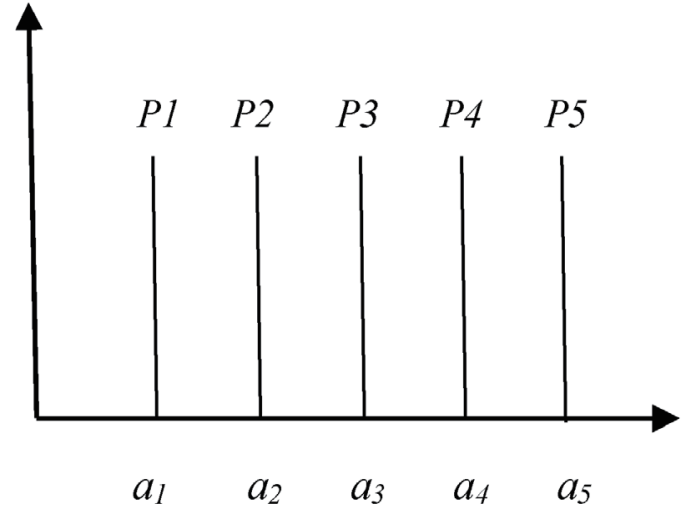

Fig. 6. Membership function of defuzzifier.

$$
y=c \times \frac{1-\exp \left(a \times \sum e\right)}{1+\exp \left(b \times \sum e\right)},
$$

where $y$ is the output of the neuron and $a, b$, and $c$ are constants. Here, we set $a=b=-0.1$ and $c=-1$.

\section{Experiments}

In this study, several purity controls were implemented. Figures 7(a) and 7(b) show the results of control by the adaptive fuzzy controller that we developed in the first experiment. In this experiment, the switching time is $180 \mathrm{~s}$ and the desired purities of materials $A$ and $B$ are $A=0.94$ and $B=0.96$. The actual purities produced by SMB are $A=0.94$ and $B=0.9593$.

Figures 8(a) and 8(b) show the control performance in the second experiment. In this experiment, the switching time is $180 \mathrm{~s}$ and the desired purities of materials $A$ and $B$ are $A=0.90$ and $B=0.91$. The actual purities produced by SMB are $A=0.8977$ and $B=0.9088$.

Figures 9(a) and 9(b) show the control performance in the third experiment. In this experiment, the switching time is $178 \mathrm{~s}$ and the desired purities of materials $A$ and $B$ are $A=0.93$ and $B=0.95$. The actual purities produced by SMB are $A=0.9319$ and $B=0.9519$. 


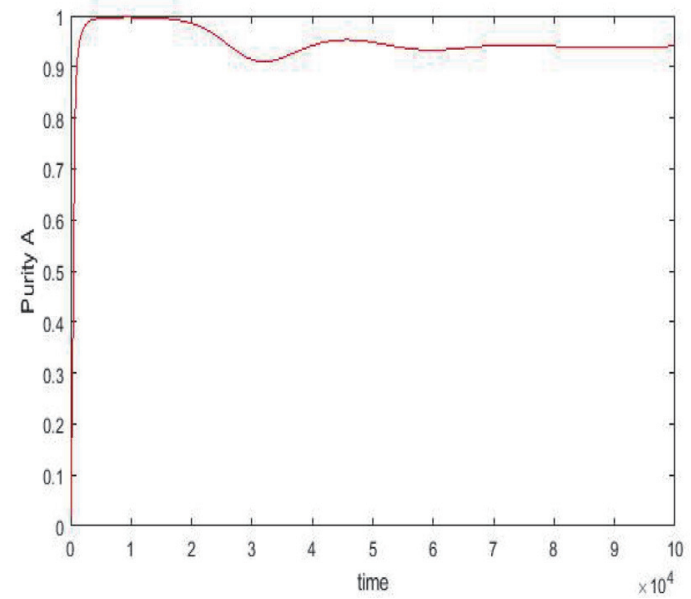

(a)

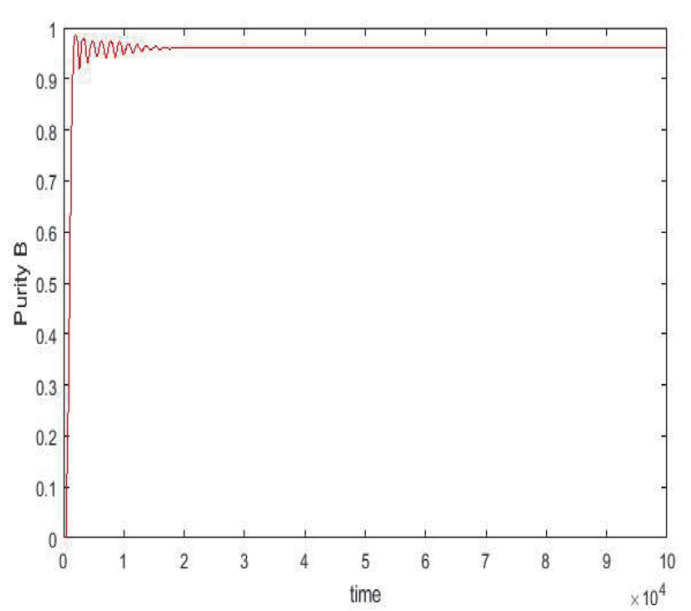

(b)

Fig. 7. (Color online) Purities of materials $A$ and $B$ produced by SMB: $A=0.94$ and $B=0.9593$.

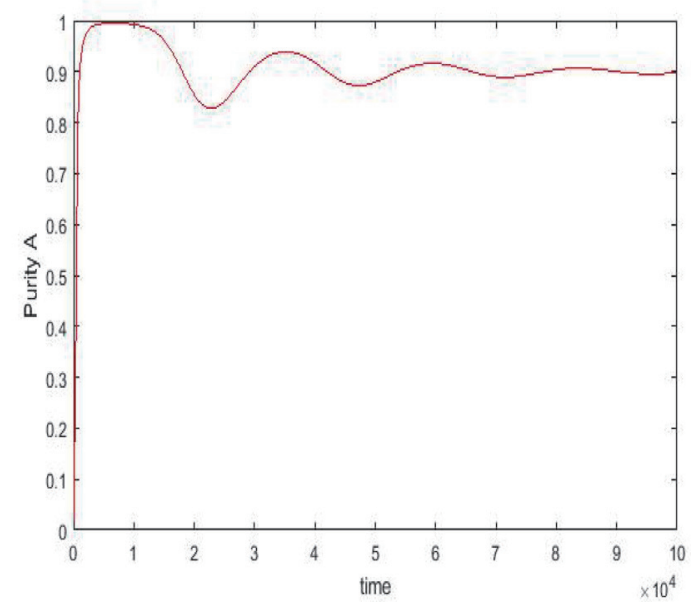

(a)

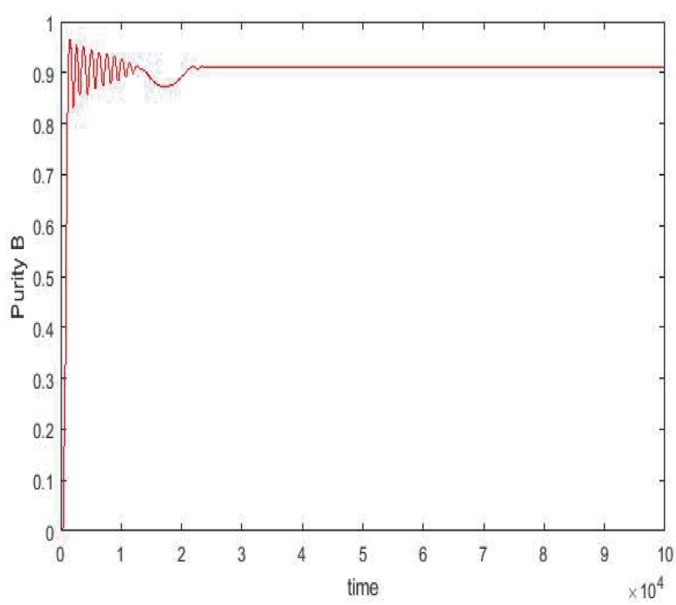

(b)

Fig. 8. (Color online) Purities of materials $A$ and $B$ produced by SMB: $A=0.8977$ and $B=0.9088$.

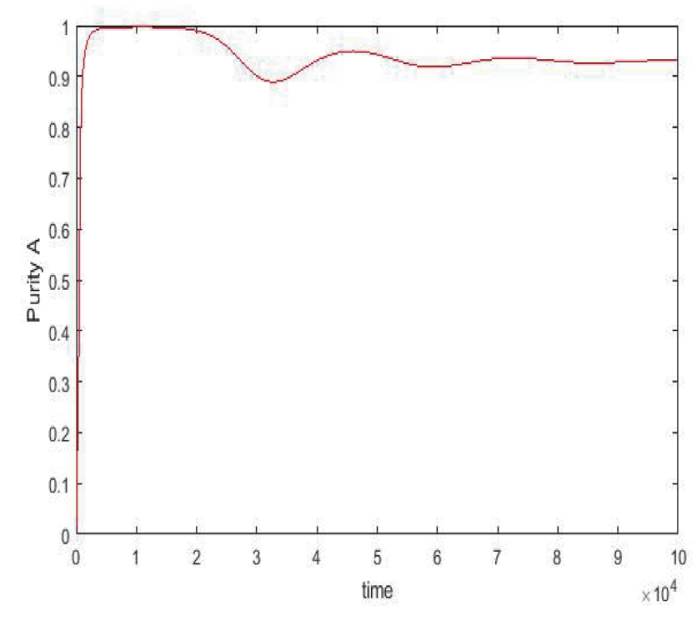

(a)

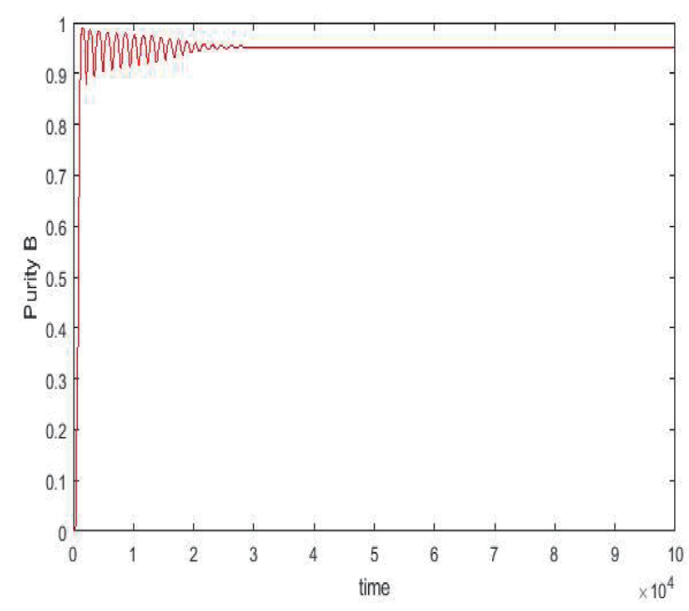

(b)

Fig. 9. (Color online) Purities of materials $A$ and $B$ produced by SMB: $A=0.9319$ and $B=0.9519$. 


\section{Conclusions}

In this study, an adaptive fuzzy control mechanism with two independent controllers for an SMB chromatographic separation system was designed and presented. In this control mechanism, the fuzzy controller is treated as the master controller, and the neuron controller functions as a slave controller in charge of fine-tuning and improving the drawback of the fuzzy controller to implement precision control. The experimental results show that the chromatographic separation of SMB can indeed be effectively and precisely controlled by using the developed adaptive fuzzy controller. The desired purities can be obtained for the separated substances.

\section{Acknowledgments}

This research was supported by the Ministry of Science and Technology, Taiwan, under Contract No. MOST-107-2221-E-214-029. Chao-Fan Xie expresses his thanks for the partial support by the Fujian Province Education Hall Youth Project (No. JAT170679) and the Fujian Natural Science Foundation Project (No. 2019J01887), China.

\section{References}

1 A. Rajendran, G. Paredes, and M. Mazzotti: J. Chromatogr. A. 1216 (2009) 709. https://doi.org/10.1016/ j.chroma.2008.10.075

2 M. Schulte and J. Strube: J. Chromatogr. A. 906 (2001) 399. https://doi.org/10.1016/S0021-9673(00)00956-0

3 C. Y. Chin and N. L. Wang: Sep. Purif. Rev. 33 (2004) 77. https://doi.org/10.1081/SPM-200042081

4 A. E. Ribeiro, P. S. Gomes, L. S. Pais, and A. E. Rodrigues: Sep. Sci. Technol. 46 (2011) 1726. https://doi.org/1 $0.1080 / 01496395.2011 .582070$

5 A. S. Andrade Neto, A. R. Secchi, M. B. Souza Jr., and A. G. Barreto Jr.: J. Chromatogr. A. 1470 (2016) 42. https://doi.org/10.1016/j.chroma.2016.09.070

6 I. B. R. Nogueria, A. M. Ribeiro, M. A. F. Martins, A. E. Rodrigues, H. Koivisto, and J. M. Loureiro: J. Chromatogr. A. 1504 (2017) 112. https://doi.org/10.1016/j.chroma.2017.04.060

7 S. Mun and N. H. L. Wang: J. Chromatogr. A. 1488 (2017) 104. https://doi.org/10.1016/j.chroma.2016.12.052

8 J. W. Lee and A. Seidel-Morgenstern: IFAC-PapersOnLine. 51 (2018) 530. https://doi.org/10.1016/ j.ifacol.2018.09.370

9 Y. Yang, X. Chen, and N. Zhang: Adsorpt. Sci. Technol. 36 (2018) 1716. https://doi. org/10.1177/0263617418804001

10 M. A. F. Martins, A. C. Zanin, and D. Odloak: Chem. Eng. Res. Des. 92 (2014) 917. https://doi.org/10.1016/ j.cherd.2013.08.005

11 M. T. Liang, R. C. Liang, L. R. Huang, K. Y. Liang, Y. L. Chieh, and J. Y. Liao: J. Taiwan Inst. Chem. Eng. 45 (2014) 1225. https://doi.org/10.1016/j.jtice.2013.10.013

12 M. T. Liang, R. C. Liang, L. R. Huang, P. H. Hsu, Y. H. Wu, and H. E. Yen: Am. J. Anal. Chem. 3 (2012) 931. https://doi.org/10.4236/ajac.2012.312A123

13 J. Yen and R. Langari: Fuzzy Logic: Intelligence, Control, and Information (Prentice Hall Inc., New Jersey, 1999) p. 183. 


\section{About the Authors}

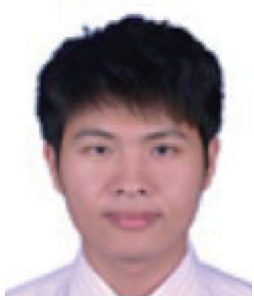

Chao-Fan Xie is currently pursuing his Ph.D. degree in I-Shou University, Taiwan. He is also a teacher at the Electronic Information Engineering Institute of Fujian Polytechnic Normal University, China. He is a member of the China Computer Association. His research areas include fuzzy control, reliability analysis, and artificial intelligence. (119396353@qq.com)

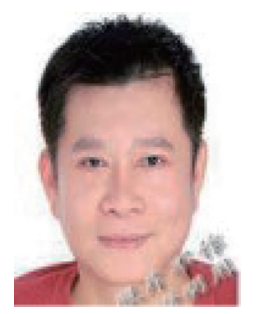

Huang-Chu Huang received his $\mathrm{Ph} . \mathrm{D}$. degree in electrical engineering from National Sun Yat-Sen University, Taiwan, in 2001. Currently, he is a professor at the Telecommunication Department, National Kaohsiung University of Science and Technology, Kaohsiung City, Taiwan. His research interests are in the areas of control, power signal prediction, and neural network applications. (h4530@nkust.edu.tw)

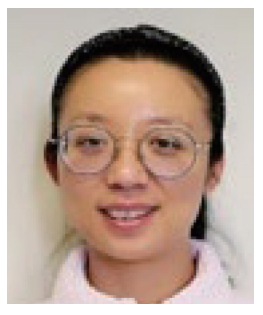

Lin Xu received her Ph.D. degree from Fujian Normal University in China. Currently, she is a teacher at the Electronic Information Engineering Institute of Fujian Polytechnic Normal University. Her research areas are machine learning and deep learning. (71471418@qq.com)

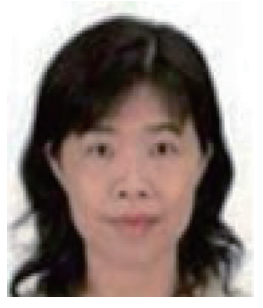

Yu-Ju Chen is currently an assistant professor of the Information Management Department at Cheng Shiu University. Her research interests include artificial intelligence, fuzzy theory, and information management. (yjchen@csu.edu.tw)

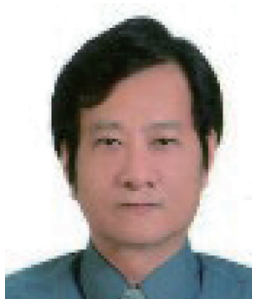

Rey-Chue Hwang received his Ph.D. degree in electrical engineering from Southern Methodist University, Dallas, TX, in 1993. Currently, he is a full professor at the Electrical Engineering Department, I-Shou University, Taiwan, R.O.C. He has published more than 300 papers in various journals and conferences in the areas of artificial intelligence systems, signal processing, and fuzzy control. He is now a fellow of IET and a senior member of IEEE. He chartered the IEEE CIS Chapter, Tainan Section and served as the co-chair and chair from 2004 to 2009. (rchwang@isu.edu.tw) 